\section{Mathematical analysis of the cellular immune reaction against tumour cells}

\author{
from R. A. De Weger, H. F. J. Dullens, R. J. De Boer and W. Den Otter
}

We have described ${ }^{1}$ a mathematical model of interaction between Tlymphocytes and macrophages ${ }^{2-5}$. In our model two different types of cytotoxic effector cells eradicate tumour cells: cytotoxic $\mathrm{T}$ lymphocytes (CTL) and cytotoxic macrophages. CTL are generated upon recognition of antigenic determinants on live, viable, tumour cells. The generation of cytotoxic macrophages, by contrast, requires processing and presentation of the tumour-associated antigens, because macrophages are activated by helper $\mathrm{T}$ cell-derived lymphokines; the helper $T\left(T_{h}\right)$ cells, in turn, can be activated by antigen-presenting cells (APC) and not by viable tumour cells. The CTL, however, proliferate in a helper-dependent fashion, i.c. in response to $T_{h}$ cell-derived interleukin 2 . The analysis of this model, by simulation on a computer, provided us with the following results:

(1) The antigenicity of a tumour cell is defined by the capacity of lymphocytes to react to it and hence to the number of precursor lymphocytes that can recognize it. It turned out from the model that tumours that differ minimally in antigenicity can differ significantly in rejectability. In the model, repeated immunization was shown to increase the number of reactive lymphocytes, the increase in helper cells yielding immunity against otherwise lethal tumour doses.

(2) The magnitude of the cytotoxic effector cell response depended on the time at which $T_{h}$ cells became activated: early helper activity strongly increased the magnitude of the response.

(3) The cytotoxic effector cell that eradicates the tumour depends on the antigenicity of the tumour cells. Poorly antigenic tumours are attacked mainly by macrophages, whereas large, highly

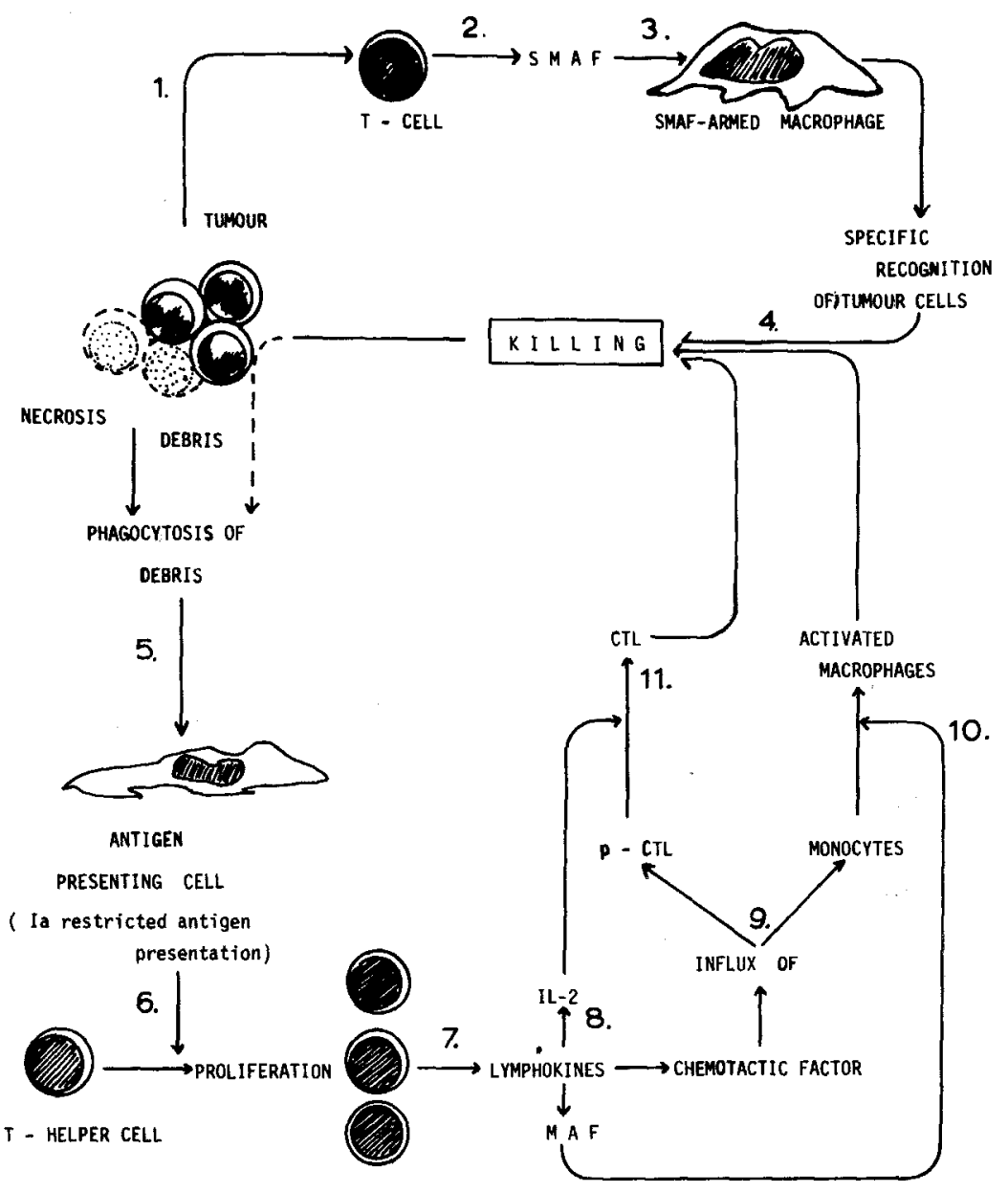

antigenic tumours can be eradicated by CTL only.

Our recent experimental results have now led us to construct a new hypothesis about the cellular immune response against tumour cells and a revised mathematical model. Currently, the induction of cellular immunity is thought to be initiated by antigens presented by APC. For induction of immunity against them, tumour cells have to die, because APC will normally not phagocytose viable tumour cells. This suggests that both intact tumour cells (irradiated or non-irradiated) and tumour cell fragments can induce tumour immunity. However, our data from studies of the mouse SL2 T-cell lymphoma indicate that this is not the case: strong tumour immunity can only be obtained with intact irradiated tumour cells. Apparently the immune system has to recognize antigenic structures at the surface of the intact cells to reject the tumour.

Furthermore, we have found that immunization with intact tumour cells leads to the induction of T lymphocytes which produce a specific macrophage arming factor (SMAF) whereas immunization with tumour cell fragments does not ${ }^{6}$. SMAF enables macrophages to recognize specifically and kill the tumour cells. SMAF production can be triggered in vitro and depends on the presence of intact tumour cells. It is independent of the presence of macrophages ${ }^{6}$. This suggests that the lymphocytes producing this factor react directly with the turnour cell antigens ${ }^{6,7}$. Immunization with tumour cell fragments induced delayedtype hypersensitivity reactions, as did immunization with intact tumour cells, but did not induce lymphocytes with the capacity to produce SMAF and transfer tumour resistance ${ }^{6}$.

Fig. 1. Schematic representation of the hypothesis concerning the tumour rejection reaction.

After injection of tumour cells $\mathrm{T}$ lymphocytes are directly stimulated to produce SMAF (steps 1 and 2). This factor adheres to (arms) resident macrophages (step 3) which are then able to kill the specific tumour cells (step 4). The debris of these tumour cells is phagocytosed by APC (step 5), that subsequently present antigens in an Ia-restricted fashion to $T_{h}$ cells (step 6 ). These stimulated $T_{\mathrm{h}}$ cells will produce lymphokines, including interleukin 2 (steps 7 and 8). The lymphokines cause an influx of mononuclear cells (step 9). Monocytes in the infiltrate will be activated by macrophage activating factor (MAF; a lymphokine) and become nonspecifically cytotoxic for tumour cells (step 10). IL-2 will stimulate the proliferation of CTL (step 11). 
We have incorporated these data and those of others, into a new hypothesis depicted in Fig. 1. This differs from the common view that the initiation of the immune response against tumour cells is independent of(tumour) antigen presentation by macrophages and that $T$ cells directly recognize tumour cells and then produce a specific T-cell factor. Among the (unpublished) experimental data supporting this hypothesis, we have found that after tumour injection the production of the specific $T$-cell factor SMAF indeed preceeds delayed-type hypersensitivity and CTL activity.

In summary, the model described by De Boer et al. was based on the assumption that all lymphokines are produced by $T_{h}$ cells, depending on antigen presentation. The revised model presented here takes account of the production of a specific $T$-cell factor (lymphokines are non-specific) and the fact that the initation of SMAF production is not dependent on antigen presentation by macrophages. The production of SMAF will lead to arming of macrophages and killing of tumour cells. Subsequently, tumour antigens can be presented by the macrophages, $T_{b}$ cells will be activated and produce lymphokines leading to generation of CTL and activated macrophages (Fig. 1). These cells will then eradicate the tumour. In this way the immune system is able to react directly after re-challenge with the antigenic cell without the necessity of cell killing, antigen processing and antigen presentation. The effect of the incorporation of these aspects will be studied by comparing the behaviour of the original and modified versions of the model.

\section{References}

1 De Boer, R. J. and Hogeweg, P. (1985) Immunology and Epidemiology. Lecture Notes in Biomathematics (in press)

2 De Boer, R. J., Hogeweg, P., Dullens, H. F. J., De Weger, R. A. and Den Otter, W. (1985) J. Immunol. 134, 2748-2758

3 Wagner, H. C., Hardt, K., Heeg, K., Pfizenmaier, W., Solbach, R., Bartlett, H., Stockinger, H. and Röllinghof, M. (1980) Immunol. Rev. 51, 215-255

4 Mizel, S. B. (1982) Immunol. Rev. 63, 51-72

5 Palacios, R. (1982) Immunol. Rev. 63, 73-110

6 De Weger, R. A., Pels, E. and Den Otter, W. (1982) Immunology 47, 541-550

7 Pels, E., De Weger, R. A. and Den Otter, W. (1984) Immunobiology 166, 84-95

R. A. De Weger, H. F.J. Dullens and W. Den Otter are at the Institute of Pathology, Pasteurstraat 2, 3511 HX Utrecht, The Netherlands, and R.J. De Boer is at the Bioinformatics Group, State University Utrecht, Padualaan 8, $3584 \mathrm{CH}$ Utrecht, The Netherlands.

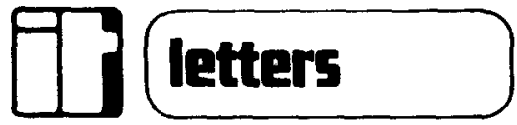

\section{Mast cells in fibrosis}

SIR,

Henry N. Claman (Immunol. Today, 1985, 6, 192) writes about a close immunopathogenic association of mast cells and fibrosis. Mast cells, however, are also associated with antiogenesis ${ }^{1}$ which is itself involved in the pathogenesis of fibrosis. This may be exemplified by the fibrosis which accompanies lower limb venous stasis and which may be indistinguishable from the fibrosis in scleroderma.

Venous stasis is characterized by a proliferation of thick-walled capillaries composed of endothelial cells, pericytes, myofibroblasts, their transitional cells, and surrounded by interstitial cells, mostly fibroblasts ${ }^{2}$. All the above mentioned cells may be Factor VIIIrelated antigen positive ${ }^{3}$ and are, therefore, vascular endothelium derived cells. In venous ulcer granulation tissue, capillaries are often surrounded by abundant mastocytes ${ }^{4}$ which act most probably as angiogenesis modulators able to stimulate endothelial cell migration by releasing their heparin ${ }^{1}$.

The appearance of venous stasis fibrosis may be explained as follows: venous hypertension damages capillaries and subsequent tissue hypoxia and inflammation stimulate a production of endogenous angiogenic factors. Angiogenesis leads to a formation of hyperplastic capillaries lined by more than one layer of endothelium or endothelium-derived cells. External endothelium-derived cells separate from hyperplastic capillaries and contribute to a formation of perivascular infiltrates. Apparently, the normal endothelial cell retains undifferentiated potential expressing itself when the cell is pushed aside by angiogenic pressure and is no more inhibited by its original environment. It then differentiates into the myofibroblast and the fibroblast able to produce the intercellular matrix characteristic for fibrosis ${ }^{5}$.

In scleroderma, autoradiographic studies ${ }^{6}$ indicate that angiogenesis is also present. It is, however, usually counterbalanced by continuing endothelial cell death, and hyperplastic capillaries may be quite inconspicuous. Myofibroblasts are present in localized scleroderma ${ }^{7}$ and the endothelial cells of 'hypertrophic appearance' or 'fibroplastic metamorphosis' ${ }^{8}$, entirely compatible with their later differentiation into perivascular myofibroblasts ${ }^{9}$, have been described in progressive systemic sclerosis.

Angiogenesis is one of the defence reactions by which the organism tries to retain homeostasis in its injured tissues. If the harmful aetiological factor (venous hypertension, immunopathological reaction) is not eliminated in due time, angiogenic pressure leads to a formation of hyperplastic capillaries, a migration of endothelial cells into the extravascular space, and a production of undemanding fibrotic and sclerotic tissues. In this way, tissue homeostasis may be re-established. Mast cells seem to play a role as angiogenesis stimulators in the pathogenesis of fibrosis. This is supported by the fact that there are fibroses in which nobody suspects immunopathological reactions but which, nevertheless, manifest an increased mast cell population. Venous stasis dermatitis is such a fibrotic process par excellence.

J. T. BERANEK J. P. GLEVY

Unité Inserm 210, Faculté de Médecine, Université de Nice, 06034 Nice, Cedex, France.

\section{References}

1 Folkman, J., Langer, R., Linhardt, R. J., Haudenschild, C. and Taylor, S. (1983) Science 221, 719-725

2 Weber, K, and Braun-Falco, O. (1973) Arch. Derm. Forsch. 248, 29-44

3 Beranek, J, T., Hsi, B.-L. and Ortonne, J.-P. (1985) Br. J. Dermatol. 113, (Suppl. 28), 128-132

4 Huriez, C. (1957) Lille Med. 2, 36-38

5 Borojevic, R., Vinhas, S. A., Monteiro, A. N. A., Domont, G. B., Zyngier, F. R. and Grimaud, J.-A. (1985) Biol. Cell 53, 231-238

6 Fleischmajer, R., Perlish, J. S., Shaw, K. V. and Pirozzi, D. J. (1976) Arch. Dermatol. 117, 1553-1557

7 Kobayasi, T. and Serup, J. (1983) Acta Derm. Venereol. 63, 321-327

8 Trotta, F. et al. (1984) Clin. Exp. Rheum. 2, 209-215

9 Kischer, C. W., Thies, A. C. and Chyapil, M. (1982) Hum. Pathol. 13, 819-824 